\title{
UV-B Exposure Increases the Activity of Indoleamine 2, 3-Dioxygenase (Ido) and Alters the Levels of Tryptophan Metabolites in Indian Ground Squirrel (Funambulus Palmarum) Lens
}

\author{
Nagalaxmi V1', Praveen Kumar M${ }^{1}$, Sashidhar RB² and Turlapati Naga Raju ${ }^{1 *}$
}

${ }^{1}$ Department of Zoology, Osmania University, Hyderabad, India

${ }^{2}$ Department of Biochemistry, Osmania University, Hyderabad, India

\begin{abstract}
The ocular lens of the ground squirrel is an excellent model for studies of eye light interactions that may apply to the human system. UV-B radiation induced damage to the eye lens is believed to be mediated through ROS. Antioxidant systems, both enzymatic and non- enzymatic aid in preventing the damage to the lens. The activity of indoleamine 2,3- dioxygenase (IDO), a first rate limiting enzyme of tryptophan catabolism, has been studied in the lenses of Indian ground squirrel exposed to UV-B radiation. Further, antioxidants and oxidative stress markers have also been investigated to assess the oxidative status. Our investigation revealed an increased indoleamine 2,3-dioxygenase activity and tryptophan metabolites suggesting their protective role in UV stress. The study indicates that UV-B irradiation for $12 \mathrm{~h}$ and $24 \mathrm{~h}\left(300 \mathrm{~nm} ; 100 \mu \mathrm{w} / \mathrm{cm}^{2}\right)$ of lens samples led to a marginal decrease in GSH and increase in carbonyls and MDA levels reflecting the role of indoleamine 2,3-dioxygenase in protecting the lens tissue.
\end{abstract}

Keywords: Indoleamine 2, 3-dioxygenase; UV-B radiation; kynurenine; 3-hydroxy kynurenine; Reactive oxygen species; Glutathione; Superoxide dismutase; Malondialdehyde

\section{Introduction}

UV-B radiation (280-320 nm) is absorbed predominantly by the outer structures of the eye, particularly the cornea, with relatively little radiation reaching the lens and retina $[1,2]$. Under natural conditions these rays are filtered partially by the ozone layer, but some still reach the earth's surface. Near-ultraviolet (UV) radiation represents around $25 \%$ of the solar spectrum and approximately $10 \mathrm{~mW} / \mathrm{cm}^{2}$ $(300-400 \mathrm{~nm})$ can impinge upon the eye from direct sunlight. Light in the near-UV range at this irradiance level is capable of photochemically damaging mammalian cells [3]. The eye thus does receive UV-B radiation, which is greatly attenuated by the time it gets past the cornea and aqueous humor before reaching the lens [4]. Yet even this amount of UV-B, incident for extended periods of time, can cause chemical and biochemical damage to the constituents of the lens causing cataract [5-7]. Ultraviolet-B (UV-B) and ultraviolet-C (UV-C) irradiation induce the oxidation of tryptophan [8]. The oxidation of tryptophan catalyzed by indoleamine 2, 3-dioxygenase (E.C 1.13.11.52) results in oxidative end products within the kynurenine pathway [9]. They are also produced, albeit, to a lesser extent, by enzymeindependent UV mediated oxidation of tryptophan [10]. Earlier observations from our laboratory with WNIN rats showed changes in indoleamine 2, 3-dioxygenase expression during cataractogenesis [11]. Tryptophan oxidation is enhanced when IDO is activated by interferon- $\gamma$ or by superoxide anion. A series of enzymatic reactions convert kynurenine to anthranilic acid (AA), 3-hydroxykynurenine (3HK) and 3-hydroxyanthranilic acid (3HAA) [12,13]. Subsequently, $3 \mathrm{HK}$ is glycosylated to form 3-hydroxykynurenine O-glucoside (3HKG). Van Heyningen [12] first reported the identification of the lens pigment in the grey squirrel (Sciurus carolinensis leucotis) as $\mathrm{N}$-acetyl-3-hydroxykynurenine and this was confirmed at a later date using more advanced techniques [3]. Major UV filters (N-acetyl 3-hydroxykynurenine and $\mathrm{N}$-acetyl-kynurenine) in the lens of the thirteen lined ground squirrel (S. tridecemlineatus) have been identified and quantified [7]. The lenses of both the grey squirrel and ground squirrel contain $\mathrm{N}$-acetyl-3-hydroxykynurenine as the major
UV filter; however, $\mathrm{N}$-acetyl-kynurenine appears to be unique to the ground squirrel. For the present investigation we have chosen Indian 3-lined ground squirrel which is found naturally in southern India. These kynurenine metabolites may also act as UV filters and reduce chromatic aberration to sharpen the retinal image. Further, they may also minimize or reduce photo-oxidative damage that may result from prolonged exposure of the lens and retina to the high energy wavelengths of light.

The lens has an efficient UV protection system that acts to ameliorate the effects of photo-oxidation. In the present study, we have measured the activity of indoleamine 2,3-dioxygenase and quantified the tryptophan metabolites in Indian ground squirrel (Funambulus palmarum) lens samples which were subjected to UV-B irradiation. Our experimental investigation indicated that exposure to UV-B light leads to an increase in indoleamine 2,3-dioxygenase activity, resulting in an increase in tryptophan metabolites (kynurenine and 3-hydroxykynurenine), which act as UV filters. Further, irradiation led to an increased lipid peroxidation and protein carbonyls and a decrease in GSH suggesting an oxidative insult.

\section{Materials and Methods}

\section{Materials}

Acetonitrile, methanol, trifluoroacetic acid (TFA), ammonium

*Corresponding author: Dr. Turlapati NagaRaju, Department of Zoology Physiology Division, University College of Science, Osmania University, Hyderabad, 500 007, India, Tel: 040-42212242; E-mail: rajutn57@gmail.com

Received October 12, 2015; Accepted December 11, 2015; Published December 21, 2015

Citation: Nagalaxmi V, Praveen Kumar M, Sashidhar RB, Naga Raju T (2015) UV-B Exposure Increases the Activity of Indoleamine 2, 3-Dioxygenase (Ido) and Alters the Levels of Tryptophan Metabolites in Indian Ground Squirrel (Funambulus Palmarum) Lens. J Diabetic Complications Med 1: 102

Copyright: (c) 2015 Nagalaxmi V, et al. This is an open-access article distributed under the terms of the Creative Commons Attribution License, which permits unrestricted use, distribution, and reproduction in any medium, provided the original author and source are credited. 
Citation: Nagalaxmi V, Praveen Kumar M, Sashidhar RB, Naga Raju T (2015) UV-B Exposure Increases the Activity of Indoleamine 2, 3-Dioxygenase (Ido) and Alters the Levels of Tryptophan Metabolites in Indian Ground Squirrel (Funambulus Palmarum) Lens. J Diabetic Complications Med 1: 102

acetate, catalase, kynurenine, 3-hydroxykynurenine, L-tryptophan, 2-thiobarbituric acid (TBA), 1,1,3,3-tetraethoxy propane (TEP), ortho-pthalaldehyde (OPT), reduced glutathione (GSH), 2,4-dinitrophenylhydrazine, diethylenetriaminepentaacetic acid (DETAPA), pyrogallol and bovine serum albumin (BSA) were obtained from Sigma Chem.co. All other chemicals and reagents used were of analytical grade.

\section{Animals}

Adult three lined ground squirrels (Funambulus palmarum), weighing approximately $150 \mathrm{~g}$, were obtained and animal care protocols were in accordance with and approved by Institutional Animal Ethics Committee (383/01/CPCSEA). Animals were sacrificed by $\mathrm{Co} 2$ asphyxiation and lenses were dissected by posterior approach.

\section{Irradiation}

Intact lenses were suspended in RPMI- 1640 medium, containing $10 \mathrm{mM}$ HEPES buffer pH 7.2 and $0.01 \%$ sodium azide ( $1 \mathrm{ml} / \mathrm{lens})$ in the quartz cuvctte by employing a perplex sheet. Lenses were irradiated at $300 \mathrm{~nm}$ at room temperature $\left(22^{\circ} \mathrm{C}\right.$ ) for different time periods (up to 24 $\mathrm{h}$ ), placed in the cuvette in such a way that the anterior portion faces the light source. Lenses kept in the dark under similar conditions served as control. The source of UV light was a $150 \mathrm{~W}$ xenon high pressure lamp attached to a double monochromator [14]. The distance between the sample holder (cuvette) and exit slit of the monochromator was 6 $\mathrm{cm}$. The intensity of the incident light falling on the sample was found to be $100 \mu \mathrm{W} \mathrm{cm}$, as measured with an ultraviolet meter (Blak-Ray, UVP Inc, Model J-225). At the end of the time period, the lenses of $12 \mathrm{~h}$ and $24 \mathrm{~h}$ corresponding to control and irradiated samples were taken, homogenized and centrifuged at $14,000 \times \mathrm{g}$ for $20 \mathrm{~min}$ at $4^{\circ} \mathrm{C}$ for indoleamine 2,3-dioxygenase, SOD and protein carbonyls. Total lens homogenate (10\%) was used to determine the levels of MDA, GSH and tryptophan metabolites.

\section{Preparation of the lens homogenate}

Four to six lenses have been pooled, weighed and $10 \%(\mathrm{w} / \mathrm{v})$ homogenate was prepared in $50 \mathrm{mM}$ sodium phosphate buffer $\mathrm{pH} 7.4$ for all assays. Lenses used for the study are categorized as follows: C12 h (Control 12 hours), C24 h (Control 24 hours), E12 h (Experimental 12 hours), E24 h (Experimental 24 hours).

\section{Protein estimation}

Protein (total, soluble and insoluble) was estimated according to Lowry [14] using BSA as reference standard. For total protein estimation the lens homogenate (10\%) was prepared in $50 \mathrm{mM}$ sodium phosphate buffer $\mathrm{pH}$ 7.4. Total homogenate was centrifuged at $14,000 \times \mathrm{g}$ for 20 $\min$ at $4^{\circ} \mathrm{C}$. The buffer soluble supernatant was used for estimation of soluble protein and the residue was dissolved in TNEN buffer $\mathrm{pH} 8.0$ [Tris buffer $25 \mathrm{mM}$ containing Nacl $(0.1 \mathrm{M})$, EDTA $(0.5 \mathrm{mM})$, and sodium azide (0.01\%)] and used for the estimation of insoluble protein.

\section{Kynurenine and 3-hydroxykynurenine standard curve by HPLC}

The standard medium $(200 \mu \mathrm{l})$ contained $0.5 \mathrm{M}$ potassium phosphate buffer $(20 \mu \mathrm{l}, \mathrm{pH} 6.5)$ at a final concentration of $50 \mathrm{mM}$, $0.2 \mathrm{M}$ ascorbic acid ( $20 \mu \mathrm{l}$, neutralized with $1 \mathrm{M} \mathrm{NaOH}$ solution) at a final concentration of $20 \mathrm{mM}, 0.5 \mathrm{mM}$ methylene blue $(4 \mu \mathrm{l})$ at a final concentration of $10 \mu \mathrm{M}, 5 \mathrm{mg} / \mathrm{ml}$ catalase $(4 \mu \mathrm{l})$ at a final concentration of $100 \mu \mathrm{g} / \mathrm{ml}$, MilliQ water $(132 \mu \mathrm{l})$ and various concentrations of kynurenine and 3-hydroxy-kynurenine $(20 \mu \mathrm{l})$. After addition of $40 \mu \mathrm{l}$ of $30 \%(\mathrm{v} / \mathrm{v}) \mathrm{TCA}$, the medium was centrifuged $\left(11,500 \mathrm{rpm}, 4^{\circ} \mathrm{C}, 15\right.$ $\mathrm{min})$. The amount of kynurenine and 3-hydroxykynurenine present in the supernatant was then measured by reversed phase HPLC using the Phenomenex column (C18, 250×4.60 mm, 4 micron), LC-20AT pump (Shimadzu), gradient controller (Shimadzu Chromatography Corp., Kyoto, Japan) and a Rheodyne injection valve with a $20 \mu \mathrm{l}$ fixed sample loop (Model 7725i, Rheodyne, Cotati, CA, USA). A binary solvent system was used as the mobile phase with a flow rate of $0.8 \mathrm{ml} / \mathrm{min}$. Ammonium acetate $(10 \mathrm{mM})$ as solvent $\mathrm{A}$ and $10 \%$ methanol in 10 $\mathrm{mM}$ ammonium acetate $\mathrm{pH} 6.7$ as solvent $\mathrm{B}$. The percentage of solvent $B$ in the gradient was $0 \%(10 \mathrm{~min}), 0-100 \%(10 \mathrm{~min})$ and $100-0 \%(15$ $\mathrm{min}$ ) and the eluant was monitored at $360 \mathrm{~nm}$ (UV-VIS detector).

\section{Assay of Indoleamine 2, 3-dioxygenase activity}

Lens homogenate was centrifuged at $14,000 \times \mathrm{g}, 4^{\circ} \mathrm{C}$, for $15 \mathrm{~min}$ and supernatant was used for the indoleamine 2,3-dioxygenase assay. The assay was carried out according to the method of Mailankot with minor modifications. The standard assay medium $(200 \mu \mathrm{l})$ contained $0.5 \mathrm{M}$ potassium phosphate buffer $(20 \mu \mathrm{l}, \mathrm{pH} 6.5)$ at a final concentration of $50 \mathrm{mM}, 0.2 \mathrm{M}$ ascorbic acid $(20 \mu \mathrm{l}$ neutralized with $1 \mathrm{M} \mathrm{NaOH}$ solution) at a final concentration of $20 \mathrm{mM}, 0.5 \mathrm{mM}$ methylene blue $(4 \mu \mathrm{l})$ at a final concentration of $10 \mathrm{M}, 5 \mathrm{mg} / \mathrm{ml}$ catalase $(4 \mu \mathrm{l})$ at a final concentration of $100 \mathrm{~g} / \mathrm{ml}, 2 \mathrm{mM} \mathrm{L}$-tryptophan $(20 \mu \mathrm{l})$ at a final concentration of $200 \mathrm{mM}$, MilliQ water $(112 \mu \mathrm{l})$ and enzyme source (total soluble protein $1 \mathrm{mg}$ equivalent protein). The reaction mixture was incubated at $37^{\circ} \mathrm{C}$ for $1 \mathrm{~h}$ and $40 \mu \mathrm{l}$ of $30 \%(\mathrm{v} / \mathrm{v})$ TCA was added to the assay mixture. The mixture was incubated at $60^{\circ} \mathrm{C}$ for 15 min to hydrolyze $\mathrm{N}$-formyl kynurenine to kynurenine. It was then centrifuged at $14,000 \times \mathrm{g}, 4^{\circ} \mathrm{C}, 15 \mathrm{~min}$ and the amount of kynurenine and 3-hydroxykynurenine formed were quantified by method outlined above. Indoleamine 2,3-dioxygenase activity was expressed as nanomoles of both kynurenine and 3-hydroxykynurenine formed per milligram protein per minute.

\section{Quantification of tryptophan metabolites by HPLC}

To $100 \mu \mathrm{l}$ of lens homogenate (control and UV irradiated samples) $0.3 \mathrm{ml}$ of $100 \%(\mathrm{v} / \mathrm{v})$ ethanol was added and placed at room temperature for $1 \mathrm{~h}$ and then centrifuged $(14,000 \times \mathrm{g}, 15 \mathrm{~min})$. The supernatant was removed, kept at $-20^{\circ} \mathrm{C}$, whereas the pellet was re extracted twice with $0.3 \mathrm{ml}$ of $80 \%$ ethanol. The supernatant was observed to be pale yellow in colour. The supernatants were pooled and dried in a speedvac concentrator (Eppendorf AG · 22331 Hamburg, Germany). Kynurenines were quantified by the method described by Hains et al. [6]. Metabolites have been estimated by reverse phase HPLC. The column was equilibrated in $0.1 \%(\mathrm{v} / \mathrm{v}) \mathrm{TFA}$, at a flow rate of $0.7 \mathrm{ml} / \mathrm{min}$. Samples were resuspended in $100 \mu \mathrm{l}$ of $0.1 \%(\mathrm{v} / \mathrm{v}) \mathrm{TFA}$, centrifuged for $10 \mathrm{~min}$ at $12,000 \times \mathrm{g}$ and loaded on to the column. UV filters (N-acetyl-3-hydroxykynurenine, N-acetyl-kynurenine, kynurenine and 3-hydroxykynurenine) were eluted with the following gradient; $0-5$ min $0 \%$ buffer B $(0.08 \%(\mathrm{v} / \mathrm{v})$ TFA, $80 \%(\mathrm{v} / \mathrm{v})$ acetonitrile, water), 5-50 $\min 0-50 \%$ B, 50-60 min $50-0 \%$ B. The eluent was monitored using UV detector at $360 \mathrm{~nm}$. In a similar way, reference kynurenine and 3-hydroxykynurenine were used to construct standard curves.

\section{Synthesis of $\alpha$ - N-acetyl-kynurenine and $\alpha$ - $\mathrm{N}$-acetyl-3- hydroxykynurenine}

Kynurenine $(2 \mathrm{mM}$ in $800 \mathrm{mM}$ sodium phosphate buffer $\mathrm{pH}$ 7.5) was taken in a reaction chamber at $37^{\circ} \mathrm{C}$ and to this $8 \mathrm{mM}$ acetic anhydride was added drop wise. The reaction was allowed for $1 \mathrm{hr}$ with continuous and gentle magnetic stirring under subdued light 
Citation: Nagalaxmi V, Praveen Kumar M, Sashidhar RB, Naga Raju T (2015) UV-B Exposure Increases the Activity of Indoleamine 2, 3-Dioxygenase (Ido) and Alters the Levels of Tryptophan Metabolites in Indian Ground Squirrel (Funambulus Palmarum) Lens. J Diabetic Complications Med 1: 102

Page 3 of 6

conditions. The final reaction mixture contained $1 \mathrm{mM}$ kynurenine in $400 \mathrm{mM}$ sodium phosphate buffer $\mathrm{pH} 7.5$ with $4 \mathrm{mM}$ acetic anhydride. The products were separated by HPLC as described above and the major components were analyzed by mass spectrometry.

\section{Liquid chromatography mass spectrometry}

Peaks were analyzed in positive ion mode using Agilent LC-MSDTrap- SL with ESI. MS settings were as follows; capillary Exit 111.5 Volt, skimmer 40.0 Volt, Dry Temp (set) $355^{\circ} \mathrm{C}$, Nebulizer (set) 40.00 psi, Dry Gas (set) 8.00 1/min, HV Capillary 3500 V, HV End Plate Offset $-500 \mathrm{~V}$ and mass range $50-500 \mathrm{~m} / \mathrm{z}$.

\section{Oxidative stress markers and antioxidants}

Protein carbonyl content of soluble protein was measured spectrophotometrically using the 2,4-dinitrophenyl-hydrazine $[15,16]$. Malondialdehyde (MDA) production was determined by thiobarbituric acid reactive substances (TBARS) [17]. Reduced glutathione was estimated by the spectroflourimetric method reported by [18]. Total superoxide dismutase (SOD, E.C 1.15.1.2) activity was assayed by [19] monitoring the rate of inhibition of pyrogallol reduction. One unit of SOD represents the amount of enzyme required for $50 \%$ inhibition of pyrogallol reduction/min.

\section{Statistical Analysis}

The differences between the control and UV irradiated samples were analyzed using simple $\mathrm{t}$ - test and the differences were considered significant if $\mathrm{p}<0.05$. All data is expressed as mean $\pm \mathrm{SD}$.

\section{Results}

The present study is an attempt to understand the role of indoleamine 2,3-dioxygenase and antioxidants under UV-B stress. Indoleamine 2,3-dioxygenase enzyme was assayed by the method described [9] with minor changes. Enzyme activity was expressed as the quantity of both kynurenine and 3-hydroxykynurenine (Table 1) formed and standard graphs were plotted. The retention times for 3-hydroxykynurenine and kynurenine are 11 and $21 \mathrm{~min}$ respectively. Significant $(\mathrm{p}<0.05)$ increase in 3-hydroxykynurenine and marginal increase in kynurenine (Figure 1) was observed when lens homogenate was exposed to UV-B irradiation for $12 \mathrm{~h}$ in relation to control and 24 $\mathrm{h}$ UV exposure (Figure 2) led to a significant $(\mathrm{p}<0.05)$ increase in both kynurenine and 3-hydroxykynurenine.

\section{Content of kynurenines in control and UV-B irradiated groups}

A typical HPLC profile of the UV filters in control and experimental ( $12 \mathrm{~h}$ and $24 \mathrm{~h}$ ) of the ground squirrel lens homogenate is depicted in (Figure 3). All the four metabolites viz.,Kynurenine, 3-hydroxykynurenine, $\mathrm{N}$-acetyl-3-hydroxykynurenine and $\mathrm{N}$-acetylkynurenine in squirrel lens were quantified (Table 2) by HPLC. Mass spectrometry was carried out to confirm their conversion and mass values were in agreement with those reported in literature [7] several major peaks have been observed that absorbed at $360 \mathrm{~nm}$. Our data confirms the conversion of 3-hydroxykynurenine to N-acetyl-3hydroxyKynurenine and a clear cut wavelength shift was also observed. As a result of conversion, the maximum absorption of $\mathrm{N}$-acetyl-3hydroxyKynurenine was recorded at $300 \mathrm{~nm}$. A marginal increase in both 3-hydroxykynurenine and kynurenine for $12 \mathrm{~h}$ exposure and significant $(\mathrm{p}<0.05)$ increase in kynurenine for $24 \mathrm{~h}$ exposure was observed. However, the levels of $\mathrm{N}$-acetyl-3-hydroxykynurenine and N-acetyl-kynurenine were found to be unaltered in both $12 \mathrm{~h}$ and $24 \mathrm{~h}$ exposures. The $\mathrm{a}$-amino groups of both Kynurenine and 3-hydroxykynurenine can act as acceptors for the acetyl group suggesting an efficient lenticular mechanism for acetylation of the $a$-amino group of these metabolites. Acetylation of the $\alpha$-amino group will prevent the deamination of the tryptophan derived UV filters and this perhaps represents an efficient mechanism for stabilizing UV filters in the squirrel lens (Figure 4).

\section{Protein content}

There was no net change in the soluble and insoluble protein content (Table 3$)$ in both control and UV-B (12 h and $24 \mathrm{~h}$ ) exposed samples.

\section{Antioxidants}

In oxidative stress, the parameters commonly considered are glutathione (GSH), superoxide dismutase (SOD), malondialdehyde

\begin{tabular}{|c|c|c|}
\hline Groups & KYN (1mg protein) & 3-OHKYN (1mg protein) \\
\hline C 12 h & $0.05 \pm 0.01$ & $2.24 \pm 0.03$ \\
\hline E 12 h & $0.09 \pm 0.01$ & $3.94 \pm 0.08^{*}$ \\
\hline C 24 h & $0.03 \pm 0.00$ & $3.02 \pm 0.04$ \\
\hline E 24 h & $0.05 \pm 0.00^{*}$ & $3.80 \pm 0.39^{*}$ \\
\hline
\end{tabular}

IDO measured using nanomoles of kynurenine and 3-hydroxykynureninne formed per milligram protein per minute. Values are mean $\pm S D(n=3)$. The * indicates the significance $p<0.05$. [C (Control); $E$ (Experimental)]

Table 1: Effect of UV-B irradiation on IDO activity in squirrel lens homogenate.

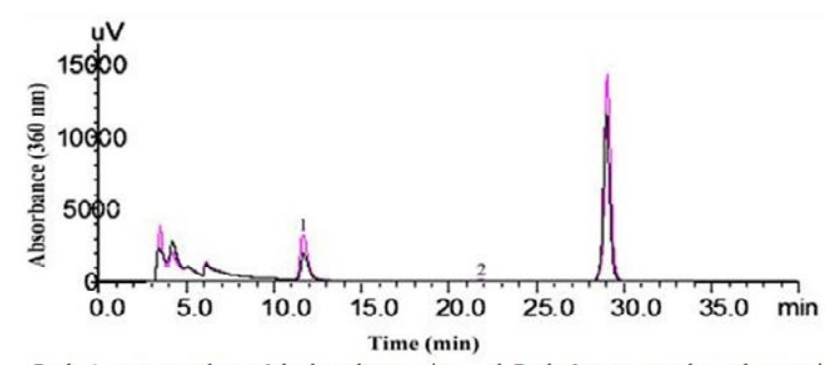

Peak 1 corresponds to 3-hydroxykynurenine and Peak 2 corresponds to kynurenine. 3-hydroxykynurenine and kynurenine present in the control and experimental samples match with the standards of 3-hydroxykynurenine (RRT $11 \mathrm{~min}$ ) and kynurenine (RRT 21 $\min$

Figure 1: Represents the control $12 \mathrm{~h}$ and experimental $12 \mathrm{~h}$ IDO enzyme assay HPLC profile.

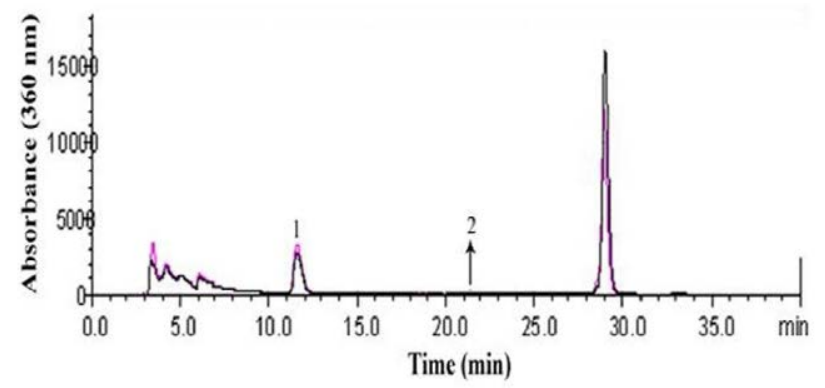

Peak 1 conesponds to 3-hydroxykynuremine and peak 2 conesponds to kynuremine. Figure 2: Represents the control $24 \mathrm{~h}$ and experimental $24 \mathrm{~h}$ IDO enzyme assay HPLC profile. 
Citation: Nagalaxmi V, Praveen Kumar M, Sashidhar RB, Naga Raju T (2015) UV-B Exposure Increases the Activity of Indoleamine 2, 3-Dioxygenase (Ido) and Alters the Levels of Tryptophan Metabolites in Indian Ground Squirrel (Funambulus Palmarum) Lens. J Diabetic Complications Med 1: 102.

Page 4 of 6

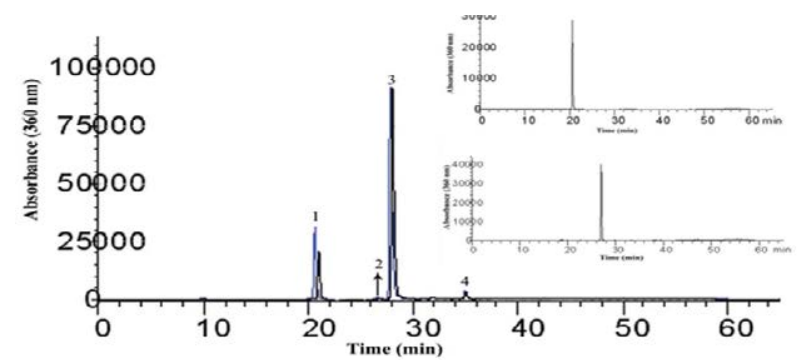

Peak 1, 2, 3 and 4 conresponds to 3-hydroxykynurenine, kynurenine, N-acetyl- 3hydroxykynurenine and $\mathrm{N}$-acetyl-kynurenine respectively. 3-hydroxykynurenine and kynurenine present in the control and experimental samples match with the standards of 3 hydroxykynurenine (RRT $20 \mathrm{~min}$ ) and kynurenine (RRT $26 \mathrm{~min}$ ). Inset: Standard 3hydroxykynurenine (RRT $20 \mathrm{~min}$ ) and standard kynurenine (RRT $26 \mathrm{~min}$ ).

Figure 3: Represents the UV filters in $\mathrm{C} 12 \mathrm{~h}$ and $\mathrm{E} 12 \mathrm{~h}$ exposure in squirrel lens homogenate.

\begin{tabular}{|c|c|c|c|c|}
\hline Groups & 3-OHKYN(nM) & KYN( $\boldsymbol{\mu M})$ & NAK(nM) & NA3OHK(nM) \\
\hline C 12 h & $7.44 \pm 0.68$ & $0.14 \pm 0.28$ & $1.55 \pm 0.37$ & $1.04 \pm 0.08$ \\
\hline E 12 h & $12.96 \pm 1.80$ & $0.26 \pm 0.04$ & $1.30 \pm 0.11$ & $0.90 \pm 0.06$ \\
\hline C 24 h & $7.08 \pm 1.84$ & $0.05 \pm 0.00$ & $1.13 \pm 0.17$ & $0.73 \pm 0.10$ \\
\hline E 24 h & $0.33 \pm 0.03^{*}$ & $0.33 \pm 0.03^{*}$ & $0.79 \pm 0.02$ & $0.56 \pm 0.01$ \\
\hline
\end{tabular}

Showing the quantitative HPLC profile of $12 \mathrm{~h}$ and $24 \mathrm{~h}$ UV-B exposure in squirre lens homogenate. Values are mean $\pm S D(n=3)$. The * indicates the significance $\mathrm{p}<0.05$. [C (Control); $E$ (Experimental)].

Table 2: Quantitative profile of tryptophan metabolites.

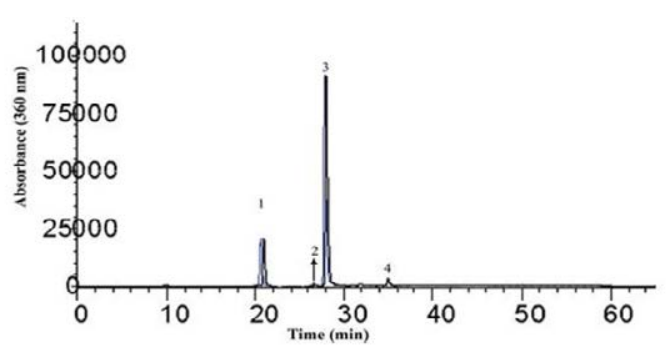

Peaks $1,2,3$ and 4 corresponds to 3-hydroxykynurenine, kynurenine, $\mathrm{N}$-acetyl- 3 hydroxykynurenine and $N$-acetyl-kynurenine respectively.

Figure 4: Represents the UV filters in $\mathrm{C} 24 \mathrm{~h}$ and E24 $\mathrm{h}$ exposure in squirrel lens homogenate.

\begin{tabular}{|c|c|c|}
\hline Groups & $\begin{array}{c}\text { Soluble protein } \\
\text { (mg/100 mg lens weight) }\end{array}$ & $\begin{array}{c}\text { Insoluble protein } \\
\text { (mg/100 mg lens weight) }\end{array}$ \\
\hline C 12 h & $31.85 \pm 2.38$ & $3.66 \pm 1.74$ \\
\hline E 12 h & $37.83 \pm 0.84$ & $4.28 \pm 0.48$ \\
\hline C 24 h & $31.72 \pm 8.65$ & $2.94 \pm 0.05$ \\
\hline E 24 h & $36.38 \pm 14.08$ & $3.84 \pm 0.08$ \\
\hline
\end{tabular}

Represents the soluble and insoluble protein content of squirrel lens homogenate. Mean $\pm S D(n=3)$. [C (Control); E (Experimental)].

Table 3: Soluble and insoluble protein content of control and UV-B exposed squirrel lens samples.

(MDA) and protein carbonyls. GSH had marginally decreased in $12 \mathrm{~h}$ UV exposure whereas, a significant $(\mathrm{p}<0.05)$ decrease in $24 \mathrm{~h}$ exposure was noticed (Table 3 ). SOD activity marginally increased when the lens sample was exposed to UV light for $12 \mathrm{~h}$. However, exposure to UV-B for a longer time $(24 \mathrm{~h})$ resulted in marginal inhibition of SOD activity (Table 3 ) in relation to the $12 \mathrm{~h}$ exposure and the activity had reverted to the control level.

\section{Oxidative stress markers TBARS and protein carbonyls content}

A marginal rise in MDA levels was observed upon $12 \mathrm{~h}$ exposure and $24 \mathrm{~h}$ UV exposure showed significant $(\mathrm{p}<0.05)$ increase (Table 4$)$ Protein carbonyls (12 h and $24 \mathrm{~h}$ UV exposures) were significantly $(p<0.05)$ higher (Table 4$)$ in irradiated groups than their corresponding control groups.

\section{Discussion}

Risk of cortical cataract mediated by UV light was reported by Heck [24]. Near-UV radiation is known to cause oxidative damage to the lens by a variety of free radical mediated reactions. In the present investigation, characteristic alterations in indoleamine 2,3-dioxygenase activity were observed in $12 \mathrm{~h} \mathrm{UV-B}$ exposure, which points to the fact that shorter duration of UV-B was found to induce the changes in enzyme activity and other concomitant changes reported herein.

The present investigation was an attempt to study direct effects of UV-B radiation in squirrel lenses in vitro on indoleamine 2,3-dioxygenase which is involved in many biological processes. Indoleamine 2,3-dioxygenase activity has been expressed by taking into consideration of the levels of both 3-hydroxykynurenine and kynurenine and this is in agreement. In the present study a significant $(\mathrm{p}<0.05)$ increase in indoleamine 2,3-dioxygenase activity has been observed in $12 \mathrm{~h}$ and $24 \mathrm{~h}$ exposure of UV-B radiation. Under normal physiological conditions indoleamine 2,3-dioxygenase activity is reported to be low $[20,21]$. However, the indoleamine 2,3-dioxygenase activity of the $24 \mathrm{~h}$ exposure was higher than that of its corresponding control lens sample. Eventhough the $24 \mathrm{~h}$ UV exposure control values decreased, the fold difference remains the same for both $12 \mathrm{~h}$ and 24 $\mathrm{h}$ exposures, indicating an increased indoleamine 2,3-dioxygenase activity under UV-B exposure. The rise in indoleamine 2,3-dioxygenase has been in agreement with the previous studies [22] which suggest its protective influence on corneal endothelial cells mediated by UV by reducing rate of apoptosis and lipid peroxidation. It has been previously reported that indoleamine 2,3-dioxygenase is an antioxidant enzyme since it happens to be a direct scavenger of superoxide radicals [23] The native state of lens sample continued to be intact and this may be attributed to an increase in indoleamine 2,3-dioxygenase activity and hence not much oxidative damage has been observed during 12 $\mathrm{h}$ exposure. The increase in levels of kynurenines may be linked to an increase in indoleamine 2, 3 dioxygenase activity which cleaves the pyrrole ring of tryptophan and forms formyl kynurenine using free oxy radicals. They are also produced, albeit, to a lesser extent, by enzyme independent UV mediated oxidation of tryptophan. These kynurenine metabolites may also act as UV filters and reduce chromatic aberration to sharpen the retinal image. Further, they may also minimize or reduce photo-oxidative damage that may result from prolonged exposure of

\begin{tabular}{|c|c|c|c|c|}
\hline Groups & $\begin{array}{c}\text { LPO } \\
\left(\mathrm{nmol} / \mathrm{g}^{-1} \text { lens }\right)\end{array}$ & $\begin{array}{c}\text { GSH } \\
(\mu \mathrm{mol} / 100 \mathrm{mg} \\
\text { Lens weight) }\end{array}$ & $\begin{array}{c}\text { SOD } \\
(\mathrm{IU})\end{array}$ & $\begin{array}{c}\text { Protein carbonyl } \\
\text { content (nmol/1mg } \\
\text { protein) }\end{array}$ \\
\hline C 12 h & $3.70 \pm 0.42$ & $0.17 \pm 0.01$ & $62.17 \pm 15.73$ & $3.84 \pm 0.29$ \\
\hline E 12 h & $4.50 \pm 0.01$ & $0.13 \pm 0.02$ & $74.10 \pm 12.59$ & $6.14 \pm 0.32^{*}$ \\
\hline C 24 h & $4.25 \pm 0.35$ & $0.08 \pm 0.01$ & $61.06 \pm 14.05$ & $3.77 \pm 0.18$ \\
\hline E 24 h & $9.75 \pm 0.03^{*}$ & $0.02 \pm 0.01^{*}$ & $50.17 \pm 9.27$ & $5.54 \pm 0.13^{*}$ \\
\hline
\end{tabular}

Effect of UV-B on lipid peroxidation, glutathione concentration, superoxide dismutase and protein carbonyl content in ground squirrel. The data presented here is mean $\pm S D(n=3)$. The * indicates the significance $p<0.05$. [C (Control); $E$ (Experimental)]

Table 4: Effect of UV-B irradiation on various biochemical parameters. 
Citation: Nagalaxmi V, Praveen Kumar M, Sashidhar RB, Naga Raju T (2015) UV-B Exposure Increases the Activity of Indoleamine 2, 3-Dioxygenase (Ido) and Alters the Levels of Tryptophan Metabolites in Indian Ground Squirrel (Funambulus Palmarum) Lens. J Diabetic Complications Med 1: 102

Page 5 of 6

the lens and retina to the high energy wavelengths of light.

John had reviewed the activity of IDO in relation to tryptophan metabolism [23]. This review clearly indicates that $>95 \%$ of tryptophan is channelized through kynurenine pathway. Upon UV exposure tryptophan metabolites such as kynurenine, 3-hydroxy kynurenine are also formed and, it can be speculated that based on the previous studies, under UV exposure it is quite logical to infer that almost all the tryptophan would be oxidized through the kynurenine pathway as well as the UV derived tryptophan derivatives due to enhanced IDO activity whose presence was reported by Heck [24]. This could perhaps be the reason that no detectable tryptophan was recorded in the present investigation after UV exposure.

Our observations suggest that $\mathrm{N}$-acetyl-3-hydroxykynurenine is the major UV filter in the ground squirrel lens and besides this, 3-hydroxykynurenine and kynurenine have also been found in reduced amounts. $\mathrm{N}$-acetyl-kynurenine is unique to ground squirrel but its concentration is far less when compared to $\mathrm{N}$-acetyl-3hydroxykynurenine. Our observations revealed a significant $(\mathrm{p}<0.05)$ elevation in kynurenine for $24 \mathrm{~h}$ exposure and other metabolites remain unchanged for both $12 \mathrm{~h}$ and $24 \mathrm{~h}$ exposures indicating a protective mechanism. Besides this, 3-hydroxykynurenine was also found to show a marginal increase for $12 \mathrm{~h}$ exposure (Figure 5).

The role of glutathione (GSH), as an essential and primary lenticular antioxidant is well known. Exposure for $12 \mathrm{~h}$ showed a marginal fall in GSH content and exposure for $24 \mathrm{~h}$ clearly demonstrated a significant $(p<0.05)$ depletion of GSH $[25,26]$. This perhaps suggests the generation of oxyradicals in the lens homogenate mediated by UV-B stress and the impaired lens antioxidant status may be correlated to increase in ROS, as evidenced by decrease in GSH content.

SOD plays an important role as an antioxidant protein by reducing the level of intracellular superoxide radical induced by extracellular stimuli such as UV radiation. In the present study, the change in SOD activity suggests the release of superoxide radicals mediated through UV-B exposure. SOD activity marginally increased when the lens sample was exposed to UV for $12 \mathrm{~h}$, suggesting an activation of SOD by scavenging superoxide radical to protect the lens from UV stress. It has been reported that an increase in SOD activity is probably a response to increased ROS generation [26]. However, exposure to UV light for longer duration $(24 \mathrm{~h})$ resulted in marginal inhibition of SOD activity in comparison with the $12 \mathrm{~h}$ exposure, and the activity reverted to the control level. This is in accordance with the earlier findings which suggest that the longer duration of UV exposure suppresses the activity of SOD.

Protein carbonyl content was found to be significantly elevated in lens homogenate exposed to UV-B for $12 \mathrm{~h}$ and $24 \mathrm{~h}$ exposures in relation to control suggesting UV-B mediated oxidative stress. Protein carbonyls tend to get accumulated on the side chains of proteins as a result of oxidative stress [26]. MDA, a major oxidation product of peroxidized polyunsaturated fatty acids, has been used to determine the degree of lipid peroxidation and as a biological marker of oxidative stress. A marginal rise in lipid peroxidation has been observed in 12 $\mathrm{h}$ exposure. This marginal rise of MDA may be due to the enhanced activities of antioxidant enzymes which can scavenge excess lipid peroxidation. And, a significant $(\mathrm{p}<0.05)$ increase was noticed upon 24 $\mathrm{h}$ exposure in relation to control. These results are in agreement with the observation of [14] and Reddy [13] who reported variations in lipid peroxidation and GSH in rat lens subjected to UV-B radiation.

Our observations have revealed that squirrel lens homogenate exposed to UV-B light has led to an increase in IDO activity and tryptophan metabolites. Among UV radiation blocking compounds, certain aromatic amino acids of proteins, such as tryptophan and its metabolites including kynurenine and 3-hydroxykynurenine play a key role as UV filters in lenticular tissue by absorbing UV radiation between 300 to $400 \mathrm{~nm}$ and thus protecting both the lens and the retina from photo-oxidative damage. Keeping all this in view and based on previous findings we hypothesize that indoleamine 2,3-dioxygenase renders distinct a protective influence against UV damage in squirrel lens.
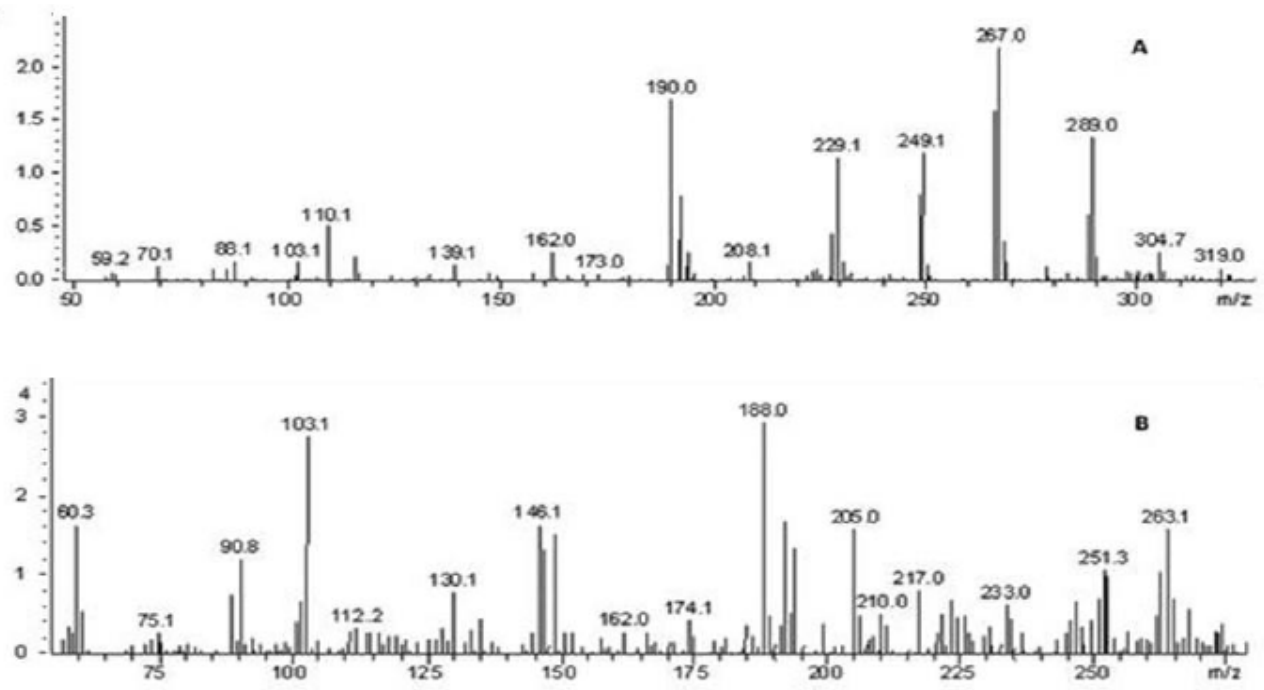

(A) N-acetyl-3-hydroxykynurenine m/z 267.0 (B) N-acetyl-kynurenine m/z 251.0

Figure 5: Shows ESI-MS of tryptophan metabolites from the ground squirrel lens 
Citation: Nagalaxmi V, Praveen Kumar M, Sashidhar RB, Naga Raju T (2015) UV-B Exposure Increases the Activity of Indoleamine 2, 3-Dioxygenase (Ido) and Alters the Levels of Tryptophan Metabolites in Indian Ground Squirrel (Funambulus Palmarum) Lens. J Diabetic Complications Med 1: 102.

\section{Acknowledgement}

N.Laxmi and T.N.R sincerely thank University Grants Commission (UGC), INDIA, for awarding of JRF fellowship and Emeritus Professor respectively.

\section{References}

1. Dillon J, Atherton SJ (1990) Time resolved spectroscopic studies on the intact human lens. Photochem and Photobiol 51: 465-468.

2. Sliney DH (1986) Physical factors in cataractogenesis: ambient ultraviole radiation and temperature. Invest Ophthalmol Vis Sci 27: 781-790.

3. Zigman S, Paxhia T (1988) The nature and properties of squirrel lens yellow pigment. Exp Eye Res 47: 819-824.

4. Balasubramanian D (2000) Ultraviolet radiation and cataract. Journal of Ocular Pharmacology and Therapeutics 16: 285-297.

5. Dillon J (1994) UV-B as a pro-aging and pro-cataract factor. Documenta Ophthalmologica 88: 339-344.

6. Hains PG, Simpanya MF, Giblin F, Truscott RJ (2006) UV filters in the lens of the thirteen lined ground squirrel (Spermophilus tridecemlineatus). Exp Eye Res 82: 730-737.

7. Nakazawa Y, Takehana M, Okab M, Shibuya F, Katakawa J, et al. (2009) UV-B irradiation-induced electron transfer between 3-hydroxykynurenine and tryptophan. J. Biol. Macromol 9: 13-22.

8. Takikawa O, Yoshida R, Kido R, Hayaishi O (1986) Tryptophan degradation in mice initiated by indoleamine 2,3-dioxygenase. J Biol Chem 261: 3648-3653.

9. de La Rochette A, Birlouez-Aragon L, Silva E, Morliere P (2003) Advanced glycation endproducts as UVA photosensitizers of tryptophan and ascorbic acid: consequences for the lens. Biochim Biophys Acta 1621: 235-241.

10. Kanth VR, Lavanya K, Srinivas J, Raju TN (2009) Elevated Expression of Indoleamine 2,3-Dioxygenase (IDO) and Accumulation of Kynurenic Acid in the Pathogenesis of STZ-Induced Diabetic Cataract in Wistar Rats. Curr Eye Res 34: 516-516

11. Stone TW (2000) Inhibitors of the kynurenine pathway. Eur J Med Chem 35 179-186.

12. Van Heyningen R (1971) Fluorescent glucoside in the human lens. Nature 230 393-394.

13. Reddy GB, Bhat KS (1998) UVB irradiation alters the activities and kinetic properties of the enzymes of energy metabolism in rat lens during aging. $J$ Photochem Photobiol B 42: 40-46.
14. Lowry OH, Rosebrough NJ, Farr AL, Randall RJ (1951) Protein measurement with the Folin phenol reagent J Biol Chem 193: 265-275.

15. Uchida K, Kanematsu M, Sakai K, Matsuda T, Hattori N, et al. 1998. Proteinbound acrolein: potential markers for oxidative stress. Proceedings of the National Academy of Sciences of the United States of America 95: 4882-4887.

16. Bhuyan KC, Bhuyan DK, SM P (1981) Evidence of increased lipid peroxidation in cataracts. IRCS Medical Science 9: 126-127.

17. Hissin PJ, Hilf R (1976) A fluorometric method for determination of oxidized and reduced glutathione in tissues. Anal Biochem 74: 214-226.

18. Marklund S, Marklund G (1974) Involvement of the superoxide anion radical in the autoxidation of pyrogallol and a convenient assay for superoxide dismutase. Eur J Biochem 47: 469-474.

19. Dang YH, Dale WE, Brown OR (2000) Comparative effects of oxygen on indoleamine 2,3-dioxygenase and tryptophan 2,3-dioxygenase of the kynurenine pathway. Free Radical Biology and Medicine 28: 615-624.

20. Terness P, Bauer TM, Rose L, Dufter C, Watzlik A, et al. (2002) Inhibition of allogeneic $T$ cell proliferation by indoleamine 2,3-dioxygenase-expressing dendritic cells: Mediation of suppression by tryptophan metabolites. J Exp Med 196: 447-457.

21. Serbecic N, Beutelspacher SC (2006) Indoleamine 2,3-dioxygenase protects corneal endothelial cells from UV mediated damage. Exp Eye Res 82: 416-426.

22. Mafia K, Gupta R, Kirk M, Wilson L, Srivastava OP, et al. (2008) UV-A-induced structural and functional changes in human lens deamidated alphaB-crystallin Mol Vis 14: $234-248$

23. John S, Kale M, Rathore N, Bhatnagar D (2001) Protective effect of vitamin E in dimethoate and malathion induced oxidative stress in rat erythrocytes. J Nutri Biochem 12: 500-504.

24. Heck DE, Vetrano AM, Mariano TM, Laskin JD (2003) UVB light stimulates production of reactive oxygen species: unexpected role for catalase. J Biol Chem 278: 22432-22436.

25. Polte T, Tyrrell RM (2004) Involvement of lipid peroxidation and organic peroxides in UVA-induced matrix metalloproteinase-1 expression. Free Radic Biol Med 36: 1566-1574

26. Krishnan N, Kodrik D (2006) Antioxidant enzymes in Spodoptera littoralis (Boisduval): Are they enhanced to protect gut tissues during oxidative stress? J Insect Physiol 52: 11-20. 